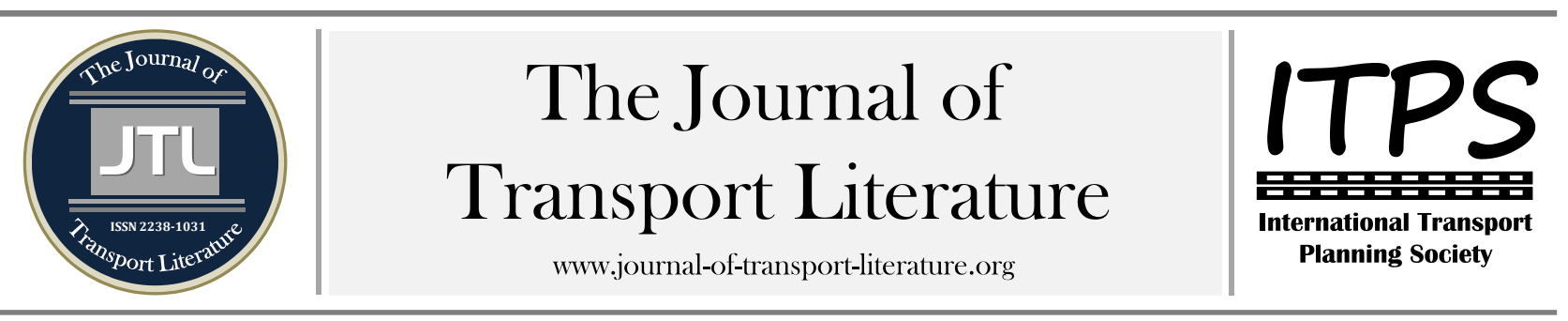

\title{
Ensaio sobre os nós das redes logísticas
}

Orlando Fontes Lima Jr ${ }^{+}$

LALT UNICAMP, Campinas, Brasil

\section{Article Info}

Palavras-chave:

Terminais

Redes

Plataforma Logística

Submitted 21 Jun 2015;

received in revised form 5 Sep 2015

accepted 15 Sep 2015

Licensed under

Creative Commons

CC-BY 3.0 BR.

\section{Resumo}

0 objetivo deste ensaio é discutir, sob o prisma epistemológico e em alguns aspectos ontológicos, os nós das redes logísticas. Analisando-se a literatura técnica e a pratica relacionada a este tema nos últimos 70 anos percebe-se algumas mudanças de paradigmas na definição e na função destes nós. Nesta discussão são considerados três elementos indicativos de rupturas epistemológicas. Serão eles mudanças nos aspectos semióticos, nas relações causais e no contexto. Em termos semióticos, os pontos de término ou de início de um movimento de mercadorias e pessoas sempre foi objeto de estudo e de atenção dos acadêmicos e dos práticos da área de transportes e de logística. Diversas relações causais e modelos explicativos para entendimento e representação de operações logísticas tratam os nós das redes logísticas como componente essencial das cadeias de suprimentos e vem se alterando ao longo do tempo. Em termos de contexto duas são as grandes alterações que condicionam a logística e consequentemente os nós de suas redes. São elas: as diferentes eras econômicas e a alteração do objeto movimentado. Porto, aeroporto, terminal, centro logístico ou plataforma logística: Qual o termo mais adequado? Depende do contexto de sua utilização e do papel exercido pelos mesmos na rede logística, todos são pontos fixos das redes sócio técnica informacionais que garantem os fluxos locais e globais.

+ Corresponding author. Universidade Estadual de Campinas, Faculdade de Engenharia Civil, Arquitetura e Urbanismo, Departamento Geotecnia e Transportes. Rua Albert Einstein n 951 sala 11. Distrito de Barão Geraldo. 13083-970 - Campinas, SP - Brasil.

E-mail address: oflimaj@fec.unicamp.br.

\section{Introdução}

Este mesmo texto na década passada provavelmente se chamaria Ensaio sobre os elos das cadeias logísticas e se fosse há três décadas, ensaio sobre terminais de carga.

Daí o objetivo deste ensaio: discutir sob o prisma epistemológico e em alguns aspectos ontológicos os nós das redes sócio técnica informacionais (Santos,1984) que permitem as operações logísticas das cadeias de suprimentos globais e, ou locais.

Analisando-se a literatura técnica e a pratica relacionada a este tema nos últimos 70 anos percebe-se algumas mudanças de paradigmas na definição e na função destes nós. (Ballou, 2007)

Rupturas epistemológicas ou quebras de paradigmas, como sugerido por KHUN (1970) ocorrem quando alguns elementos se alteram significativamente e criam necessidades de se refazer conceitos, métodos e técnicas de uma dada área da ciência.

Desconsiderando aqui a polemica existente de que administração pode ou não ser considerada ciência e consequentemente se logística é ou não disciplina passível de uma discussão epistemológica, será utilizado o mesmo ferramental desta área da filosofia para desenvolver este ensaio.

Nesta discussão serão considerados três elementos indicativos de rupturas epistemológicas. Serão eles mudanças nos aspectos semióticos, nas relações causais e no contexto.

\section{Conceitos e Definições associados aos nós das redes logísticas}

Em termos semióticos, os pontos de término ou de início de um movimento de mercadorias e pessoas sempre foi objeto de estudo e de atenção dos acadêmicos e dos práticos da área de transportes e de logística.

0 termo utilizado para sua denominação reflete o paradigma associado a abordagem logística da época em questão.

Até a década de 60 o uso apenas dos termos Porto e Aeroporto enfatizavam a vinculação ao modo de transporte preponderante. Embora existissem operações de carga e descarga de modais terrestres (trem e caminhão) nestas instalações, estes termos representam forte associação ao navio e ao avião, respectivamente.

Uma pequena alteração no conceito surge nos anos seguintes com o uso do termo terminal permitindo a inclusão dos outros modos de transportes. Portos e Aeroportos podem abrigar diferentes terminais de transportes (rodoviário, ferroviário, marítimos e aéreos) mas o termo reflete ainda o conceito de estanqueidade entre estes modais. Entende-se terminal marítimo o ponto onde terminam ou iniciam as operações e o transporte por navios, terminal rodoviário, local onde as operações de carga e descarga de caminhões são realizadas e assim por diante.

Traçando um paralelo com a evolução dos paradigmas da logística, proposto por POIST (1989) e apresentado na tabela 1 , pode se identificar claramente como as alterações dos paradigmas logísticos refletem na conceituação dos nós das redes. 
Tabela 1 - Comparação entre as Eras da Logística e seus Enfoques.

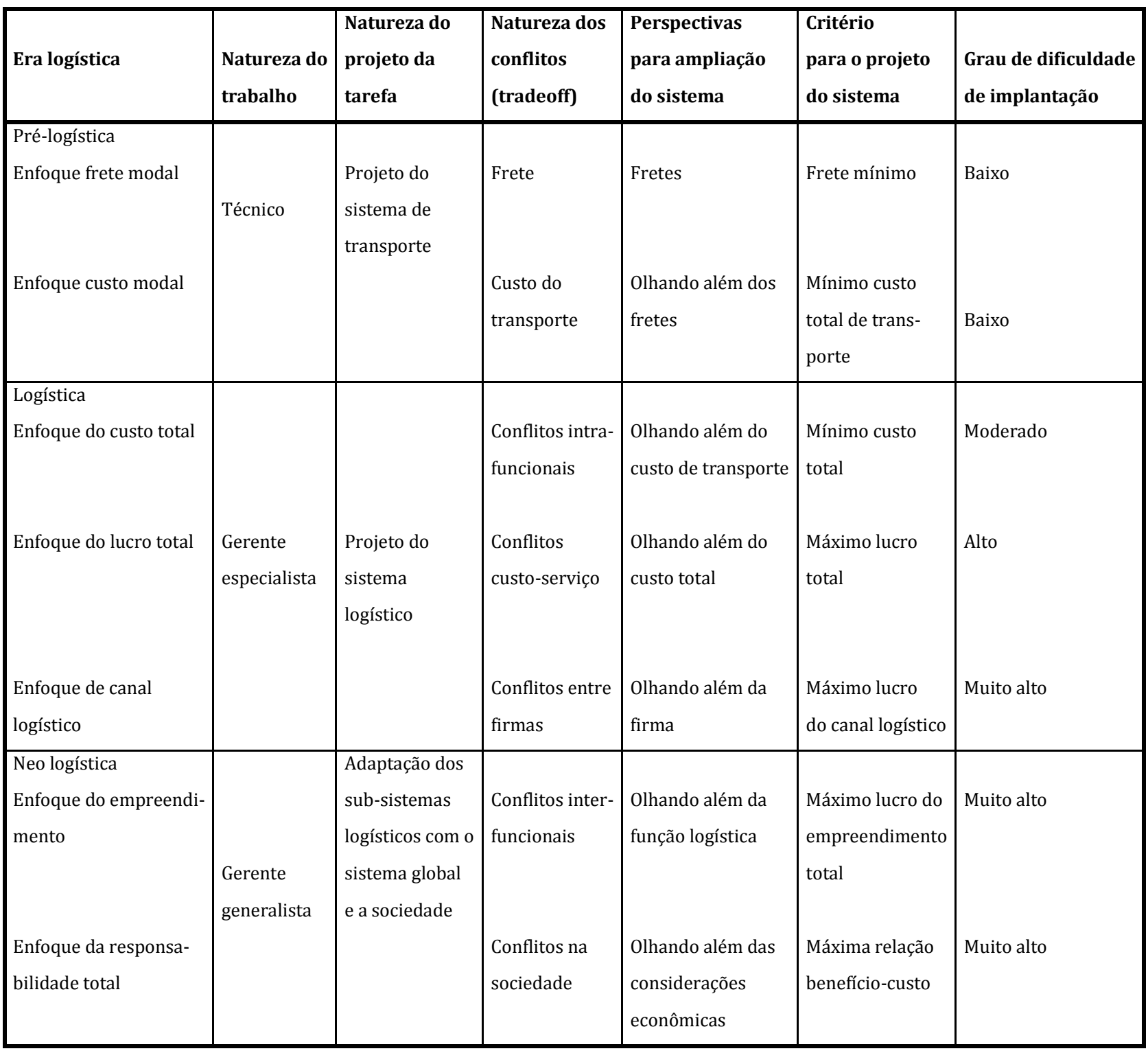

A fase funcional definida por POIST (1989) tem relação direta com o uso da terminologia porto, aeroporto e terminal para representar os nós das redes logísticas enfatizando a desconexão entre os modais. Esta terminologia evolui com adjetivação multimodal e intermodal ao termo Terminal na fase correspondente para POIST (1989) como fase da integração funcional.

Novamente as diversas discussões entre as diferenças de significado de intermodalidade e de multimodalidade que ocorrerão neste período refletem a dificuldade de se quebrar o paradigma de estanqueidade modal e incorporar os de integração modal, do custo porta a porta e da complementariedade entre modais. Esta nova terminologia carrega o significado de integração modal ou intrafuncional , como denominado por POIST (1989).

Já no momento seguinte, nos anos 90 no Brasil, a importância relativa do transporte reduz-se face as operações integradas não só entre modais, mas também, de forma mais ampla, entre transporte e estoque. Nesta fase da logística integrada, o termo Centro de Distribuição ou Centro Logístico passam a ser usados. 0 termo Centro carrega significado de relevância e de integração, destaca os aspectos espaciais e enfatiza a rede. As palavras distribuição e logística sinalizam a mudança de paradigma, substituindo a palavra transporte. Poderiam ser denominados Centros de Transportes, mas não teriam o significado necessário para adequar-se aos paradigmas da logística integrada.

Já na atualidade, no paradigma da Gestão da Cadeia de Suprimentos, o termo centro logístico passa para plataforma logística sinalizando a mudança do papel da logística nos negócios, trazendo-a para um patamar estratégico, onde deixou de ser uma restrição operacional a ser atendida e passou a ser um diferencial competitivo para o negócio.

A palavra plataforma representa bem esta nova ideia de um componente para alavancar negócios. 
Diversos outros termos são também utilizados, quer seja por diferencias regionais dos países considerados quer seja por aspectos comerciais e de marketing. A EUROPLATFORMS (2004) listam diversas destas denominações: logistics centres, Centres logistiques de fret, Gares routières de marchandises, Logistics park, Platform freight terminal, Interporto, Centro integrado de mercancias, Güterverkehrzentrum, Transport centre, Freight village e Transport center.

\section{Relações causais associadas aos nós das redes logísticas}

O segundo aspecto que sinaliza uma ruptura epistemológica está relacionado as relações de causa e efeito nos objetos de estudo e o meio. Diversas relações causais e modelos explicativos para entendimento e representação de operações logísticas tratam os nós das redes logísticas como componente essencial das cadeias de suprimentos (Ballou, 2007) e vem se alterando ao longo do tempo.

A base destes modelos tem origem em paradigmas econômicos, sociológicos e da própria logística. (Lima Jr, 2004)

Dentro de uma visão econômica, os economistas (Varian, 2012) organizam a sociedade em grupos de empresas e de famílias interagindo entre si no mercado, espaço físico ou virtual onde ocorrem as trocas visando atender as necessidades destes grupos.

Dentro de uma visão sociológica VASCONCELOS (2001) organiza a cidade em espaços de produção e de reprodução integrados por atividades de conexão que permitem a interação entre estes espaços.

Destes dois paradigmas desenvolve-se o conceito de logística com o papel de atividade meio que permite as trocas nos mercados, dentro de uma visão economia e permite as conexões entre os diferentes atores, dentro de uma visão sociológica.

Em essência processos logísticos são atividades organizadoras e integradoras de fluxos em busca de ganhos de escala, redução de custos, desmobilização de ativos e qualidade dos serviços, dentro de uma visão econômica, e mobilidade de mercadorias e pessoas, dentro de uma visão sociológica. Estes processos geram valor de espaço-tempo e de propriedade (Wild, 1979) principalmente, e em menor escala, de forma e de estado. A logística garante pessoas e coisas nos locais certos, nas horas certas e com quantidades e características certas. ( Ballou,, 2007)

As cadeias de suprimentos trocam intensamente matérias primas, produtos acabados, dinheiro, informação e responsabilidades. Fazem isso de forma bi direcional e normalmente em condições de alta variabilidade.

Neste contexto é essencial as conexões entre os agentes destas redes sócio técnica informacionais (Santos, 1984) para garantir a eficiência nas suas trocas de bens físicos, informações, dinheiro e responsabilidades. Dentro destas redes, constituídas por vias físicas ou virtuais, a integração entre elas é exercida pelos portos, aeroportos e terminais e pontos de transferência em geral.

Os processos logísticos têm como base três componentes essenciais: transporte, estoque e informação.

No caso do transporte, os modos têm características bem distintas relacionadas as suas funções e serviços. Para integralos é necessário um elemento que provoque desemparelhamento das operações entre os dois modos a serem integrados. Por exemplo se eu descarregar um caminhão diretamente no navio vou gerar uma fila muito grande e tempos ociosos para os caminhões face a diferença de escala de movimentação ( 30 t do caminhão x 30 000t do navio) Aqui surge o papel dos terminais ferroviários, portos, aeroportos com áreas de armazenagem que permitem que os ciclos operacionais de um modo de transporte ocorram de forma independente do outro ( descarrego do caminhão no armazém e o libero mesmo que o navio não esteja atracado) Este é o primeiro papel dos nós das redes logísticas: garantir desemparelhamento das operações entre os modos de transportes

No caso dos estoques, os processos produtivos têm ritmos e volumes bem definidos para serem eficientes economicamente. Se vinculamos estes processos diretamente ao atendimento das demandas de consumo em algumas situações geramos custos e ineficiências. Este é o grande desafio de técnicas como JIT, Lean 6Sigma etc. Estas armazenagens podem ser de curta duração, quase nenhuma como nas operações cross docking ou de longa duração como no caso de produtos agrícolas sazonais. Este é o segundo papel dos nós das redes logísticas: garantir o desemparelhamento entre produção e distribuição e ou consumo.

Finalmente, no caso da informação, face a complexidade dos atores envolvidos nestes processos são necessários sistemas que integrem os diferentes fluxos de informação e o façam de forma sistêmica e autômata. Este é o terceiro papel dos nós das redes logísticas: garantir a conexão, troca e o fluxo de informações nos diferentes elos destas redes.

Cabe ainda considerar que em alguns nós das redes logísticas outras atividades são exercidas sempre altamente relacionadas as anteriores. São atividades geradoras de valor de forma (produção, montagem e postponement) e de estado (serviços associados de manutenção, administrativos, telemarketing, etc)

Todos estes aspectos colocam, a partir da fase da Logística Integrada (Poist ,1989), os nós das redes em posição de destaque.

\section{Impactos do contexto nos nós das redes logísticas}

Finalmente, mudanças no contexto e no ambiente provocam rupturas epistemológicas. Em termos de contexto duas são as grandes alterações que condicionam a logística e consequentemente os nós de suas redes. São elas: as diferentes eras econômicas e a alteração do objeto movimentado. Em termos de eras econômicas, a logística inicia-se em uma era agrícola, cresce muito durante a era industrial, consolida-se na era dos serviços e hoje sofre grandes transformações, na era da informação e do conhecimento. Em termos do objeto movimentado a logística tratou sempre de bens físicos como commodities agrícolas e produtos manufaturados de baixo e de alto valores agregados. Hoje a logística depara-se com o desafio de se adaptar aos fluxos digitais e a imaterialidade dos processos de prestação de serviços e de geração de experiências. (Castells, 2002) 
Tabela 2 - 0 contexto das operações logísticas nas diferentes eras econômicas

\begin{tabular}{|c|c|c|c|c|}
\hline Economia & Agrícola & Industrial & Serviços & Experiência \\
\hline Função & Extração & Produção & Entrega & Estado \\
\hline Natureza & Tangível & Tangível & Intangível & Inesquecível \\
\hline Atributo & Natural & Padronizado & Personalizado & Pessoal \\
\hline $\begin{array}{c}\text { Método de } \\
\text { abastecimento }\end{array}$ & Em granel & $\begin{array}{c}\text { Estoques após } \\
\text { produção }\end{array}$ & $\begin{array}{c}\text { Entregue de } \\
\text { acordo com a } \\
\text { demanda }\end{array}$ & $\begin{array}{c}\text { Revelada no } \\
\text { tempo }\end{array}$ \\
\hline Vendedor & Comercio & Fornecedor & Provedor & Ator \\
\hline Comprador & Mercado & Consumidor & Cliente & Convidado \\
\hline $\begin{array}{c}\text { Fator de } \\
\text { demanda }\end{array}$ & Características & Atributos & Benefícios & Sensações \\
\hline
\end{tabular}

Adaptado de Pine II e Gilmore , 1999

\section{Conclusões}

Porto, aeroporto, terminal, centro logístico ou plataforma logística: Qual o termo mais adequado? Depende do contexto de sua utilização e do papel exercido pelos mesmo na rede logística, todos são pontos fixos das redes sócio técnica informacionais que garantem os fluxos locais e globais.

Qual será o próximo termo? Esta dúvida também é do autor deste ensaio. Se tivesse que arriscar diria que será o surgimento de lugares logísticos cada vez mais multifuncionais. Digo isso por que com o aumento da complexidade das redes logísticas tanto em termos de cobertura espacial quanto ao número de nós a tendência é a formação de tecidos logísticos, espaços contínuos onde a distribuição de produtos (no seu termo amplo) não apresenta descontinuidade. Veja o caso de distribuição de música por celular. Nestas situações os sociólogos definem (Augé, 1995) lugares como partes do espaço com significado e uso especifico para uma comunidade, que será o caso dos nós das redes logísticas e neste caso até o título do artigo terá sido vítima também de uma ruptura paradigmática.

\section{Agradecimentos}

Ao CNPq Conselho Nacional de Desenvolvimento Científico e Tecnológico e ao LALT UNICAMP pelo apoio no desenvolvimento da pesquisa.

\section{Referências}

Augé, M.(1995) Não Lugares, Letra Livre.

Castells, M. (2002) A Sociedade em Rede. A Era da Informação. Economia, Sociedade e Cultura, Volume I, Lisboa, Fundação Calouste Gulbenkian.

EuroPlatforms (2004) Logistics Centres: Directions for use. EU (http://www.unece.org/fileadmin/DAM/trans/main/eatl/docs/EN-REVWhat_is_a_Freight_VillageFinalcorretto.pdf)

Kuhn, T. S. (1970) The Structure of Scientific Revolutions. 2 ed., enlarged. Chicago and London: University of Chicago Press.

Lima Jr, O F (2004) Desempenho em serviços de transportes: Conceitos, Métodos e Práticas. Campinas, UNICAMP, Tese de Livre Docência.

Pine II, J. and Gilmore, J. H. (1999) The Experience Economy, USA.

Poist, R.F.(1989) Evolution of conceptual approaches to design business logistics systems: a sequel. Transportation Journal, v. 28, n. 3, p.3539.

Ronald H. Ballou, (2007) "The evolution and future of logistics and supply chain management", European Business Review, Vol. 19 Iss: 4 pp.332 - 34

Santos, M (1994) Técnica, espaço, tempo. São Paulo: Ed. Hucitec,

Wild, R.(1979) Production and operations management: principles and techniques. London, Holt, Rinehart and Winston.

Varian, H. R.(2012) Microeconomia - Uma Abordagem Moderna. São Paulo, 8a Ed.

Vasconcelos, E. A. (2001) Transporte Urbano, Espaço e Equidade, São Paulo, Ed Annablume. 


\section{Abstract}

The purpose of this essay is to discuss, under the epistemological prism and some ontological aspects, the nodes of logistics networks. Technical literature and practices related to this theme in the last 70 years to show some paradigm shifts in the definition and function of these nodes. In this discussion, we consider three elements to indicate epistemological ruptures: the semiotic aspects, the causal relationships and the context. In semiotic terms, the end or begin points of a goods and people movement has always been an object of study and attention of academic and practical area of transport and logistics. Several causal relationships and explanatory models for understanding and representation of logistics operations treat the nodes of logistics networks as an essential component of supply chains and has been changing over time. In terms of context there are two major changes that affect logistics and hence nodes of their networks. They are: the different economic eras and the transformation of object moved. Port, airport, terminal, logistics center or logistics platform: What is the most appropriate term? It depends on the context of their use and the role played in logistics network, all are fixed points of networks that ensure local and global flows.

Key words: terminals, networks, logistic platform. 